\title{
The Effect of Age and Activity Level on Stem Subsidence in Total Hip Arthroplasty
}

\author{
Stephen Zak, BA ${ }^{1}$ Sil Simon Greenbaum, MD ${ }^{1} \quad$ Vivek Singh, MD ${ }^{1}$ Ran Schwarzkopf, MD, MSc \\ Roy I. Davidovitch, $\mathrm{MD}^{1}$ \\ ${ }^{1}$ Department of Orthopedic Surgery, NYU Langone Health, New York, \\ New York \\ Address for correspondence Ran Schwarzkopf, MD, MSc, \\ Department of Orthopedic Surgery, NYU Langone Health, $301 \mathrm{E} 17$ th \\ J Hip Surg 2020;4:173-179. \\ St, New York, NY 10003 (e-mail: ran.schwarzkopf@nyulangone.edu).
}

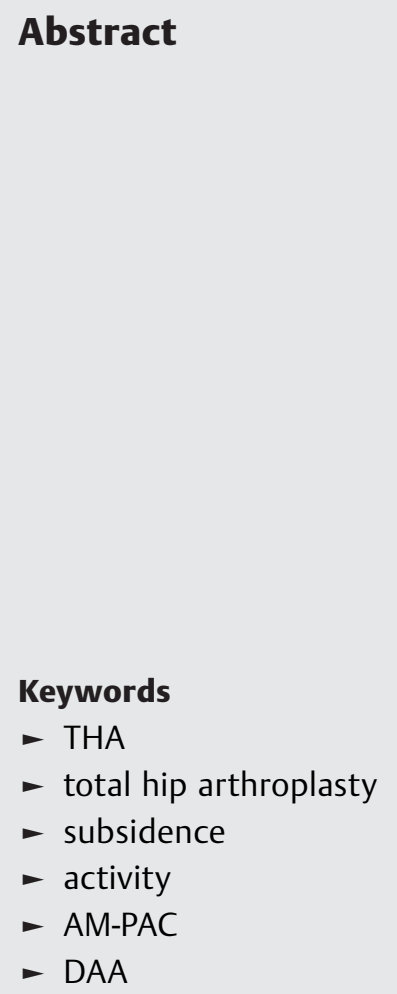

The average length of hospital stay (LOS) following total hip arthroplasty (THA) is decreasing due to a variety of factors, including rapid patient mobilization. With increased early joint loading, certain populations, such as those with low systemic bone mineral density, may be at an increased risk for early stem instability. The purpose of this study was to determine whether activity level and patient age affect femoral stem stability and early subsidence. We retrospectively reviewed 821 patients who underwent primary cementless THA. Two cohorts were established based on LOS as a proxy for activity: (1) same calendar day discharge (SDD) and (2) multiple day stay (MDS). Descriptive patient characteristics as well as surgical and clinical data including surgical time, stem alignment, and Activity Measure for Post-Acute Care (AM-PAC) scores were collected. Stem subsidence was assessed by comparing immediate postoperative radiographs with follow-up radiographs taken no less than 3 months after surgery (9.79 \pm 6.50 months). Our sample population consisted of 255 SDD (31\%) and 566 MDS (69\%) patients. Stem subsidence rate was significantly lower in the SDD than the MDS group ( 0.916 vs. $1.80 \mathrm{~mm}, p<0.001$ ). Increasing age was associated with a higher rate of stem subsidence $(\beta=0.823, p<0.001)$. Increased LOS was also associated with increased age (odds ratio $=1.092, p<0.001$ ). Higher postoperative mobility determined by AM-PAC scores was not associated with shorter LOS $(p=0.630)$. The result of this study showed increased activity level does not increase rate of subsidence in THA patients, which supports the safety and efficacy of expedited recovery programs. Increased age was found to increase stem subsidence regardless of LOS.
Advancements in surgical techniques and postoperative rehabilitation as well as standardization of postoperative protocols have led to earlier mobilization and patient discharge following total hip arthroplasty (THA). ${ }^{1-4}$ As length of stay (LOS) decreases and outpatient arthroplasty becomes increasingly common, many have sought to quantify the outcomes of these abbreviated stays. However, most of these analyses on success rates have focused on patient-centric results rather than clinical outcomes such as stem subsidence.

Femoral stem subsidence following THA has been shown to occur between 1 week and 3 months following surgery

received

June 10, 2020

accepted after revision

July 29, 2020

published online

December 1, 2020 with the largest changes occurring within the first 6 weeks. $^{5-7}$ After 3 months, little change in subsidence is seen up to 2 years postoperatively. ${ }^{6,8}$ While subsidence is seen across all patient populations, poor bone quality and aging have been associated with femoral stem subsidence. Low systemic bone mineral density (BMD) delays the osseointegration of the stem while osteoporosis and aging have been well documented as having multiple negative effects on the proximal femur including: the reduction of bone density of the trochanteric cancellous bone, increased intracortical porosity, and geometric changes. ${ }^{9-12}$ These

Copyright $\odot 2020$ by Thieme Medical Publishers, Inc., 333 Seventh Avenue, New York, NY 10001, USA.

DOI https://doi.org/ 10.1055/s-0040-1721120. ISSN 2472-8446. 
findings place older, postmenopausal females at greater risk for stem subsidence. ${ }^{9,10}$

As LOS decreases, the degree of loading on the stem following surgery is rapidly increasing as patients are more rapidly mobilized, discharged home more often, and are encouraged to move around more at home. While it has been recommended to limit postoperative activity, there is significant evidence that unrestricted weight bearing following THA does not adversely affect short- or long-term subsidence in comparison to partial weight bearing. $6,8,13,14$ In addition, others have found that bone ingrowth will occur regardless of postoperative weight bearing. ${ }^{15,16}$ These studies showed that the time until full weight bearing status did not affect postoperative stem subsidence and that initial postoperative stem fixation may play a larger role. This suggests that subsidence outcomes are influenced less by load and activity than by the biologic processes that lead to bony ingrowth.

As a greater number of patients have fast-tracked, outpatient THA, concerns over how this immediate discharge effects patient outcomes rises. Our primary objective in the present study was to analyze the effect of age and activity on stem subsidence following THA. We hypothesize that activity will not affect femoral stem subsidence, but age may have an effect due to the low BMD common in older patients.

\section{Methods}

A retrospective study was conducted on patients who underwent a primary cementless THA at a large urban academic hospital between January 2016 and October 2017. This study was approved by the institutional review board. These cases were identified using the Current Procedure Terminology code 27130 and were collected from our institution's electronic medical record. Inclusion criteria for our study included patients whose age was greater than or equal to 18 years at the time of their surgery and underwent a primary THA. Exclusion criteria included patients who were less than 18 years old or underwent a revisionTHA. Baseline patient demographic data such as age, body mass index (BMI), American Society of Anesthesiologists (ASA) score, gender, race, and smoking status were collected for all qualifying patients. Additional information including surgical time, stem type, stem alignment, LOS, Boston University Activity Measure for Post-Acute Care Short Form (AM-PAC) scores, and radiographs were also collected and analyzed. All data was recorded and deidentified using the Microsoft Excel software.

\section{Patient Population}

Our cohort consisted of 821 consecutive patients who underwent primary cementless THA. A single surgeon at a tertiary, urban, academic institution performed all surgeries using a direct anterior approach (DAA). All patients had one of two stem designs (Anthology [Smith \& Nephew] or Accolade [Stryker Orthopedics]). The choice for same-day discharge (SDD) versus inpatient stay was made through a shared decision-making process between surgeon and patient.

We retrospectively divided the cohort into two groups: (1) patients who had $\operatorname{SDD}(n=255)$ and (2) patients who had a multiple day inpatient stay (MDS) $(n=566)$. The SDD cohort consisted of $50 \%$ females and $50 \%$ males with an average age of $58.98 \pm 8.47$ years. The MDS cohort was comprised of $64 \%$ females and $36 \%$ males with an average age of $67.17 \pm 10.27$ years. The SDD cohort was discharged with limited restrictions regarding activity and weight-bearing status while the MDS cohort had a longer hospital LOS with limited opportunities to be mobile in the hospital compared with patients at home. With less assistance, greater independence, and few limitations concerning activity, SDD patients would have had a higher activity levels compared with the MDS patients who had their activity limited by hospital environment and staff.

\section{Radiologic Evaluation}

Postoperative anterior-posterior radiographic images of the hip were used to measure stem subsidence. Subsidence was measured through a comparison of most recent radiographs to immediate postoperative radiographs. The time between immediate postoperative and follow-up radiographs ranged from 3 months to 2 years. Before measurements were taken, radiographic calibration utilizing the known femoral head size was completed for each image. Measuring procedures for each image started by drawing a line parallel to the long-axis of the femoral stem followed by two perpendicular lines placed at the level of the femoral stem shoulder and the superior tip of the greater trochanter. The perpendicular distance between these parallel lines were noted ( $\mathbf{- F i g . 1} \mathbf{1}$ ). Differences between immediate postoperative and follow-up images were recorded as stem subsidence. Radiographic analysis was performed by two trained observers (J.G. and J.P.), who both agreed on the methodology that would be used throughout the measurement process. To ensure consistency, they performed alignment and subsidence measurements for the first 10 patients in the study cohort together. The interrater reliability of the first 10 measurements as calculated by the Cohen's kappa was 0.719 which demonstrates substantial agreement between the two raters and is on the higher end of interrater reliability among other studies examining subsidence. ${ }^{17,18}$ This same method used to measure subsidence was utilized to assess stem alignment (neutral, varus, valgus). The degree of varus or valgus angulation was defined as the angle formed between the central shaft of the stem and the medial or lateral endosteal cortices, respectively. As previously described in the literature, a stem was categorized into varus or valgus alignment if the angle deviated $\geq 5$ degrees from neutral. ${ }^{19-21}$

\section{AM-PAC Score Analysis}

The Boston University AM-PAC assessment is used to evaluate an individual's ability to execute important functional activities. ${ }^{22}$ We recorded and analyzed the scores of the first inpatient AM-PAC test that each patient performed. AM-PAC raw scores were converted into Centers for Medicare and Medicaid Services G-code modifiers based on Mediware's (Mediware, Lenexa, KS) conversion chart and were subsequently analyzed. ${ }^{23}$ Modifier $\mathrm{CH}$, which indicates $0 \%$ impairment, was used as our control for comparison. Other modifiers include $\mathrm{CI}$ (at least $1 \%$ but less than $20 \%$ impaired), CJ (at least 20\% but less than $40 \%$ impaired), and CK (at least 


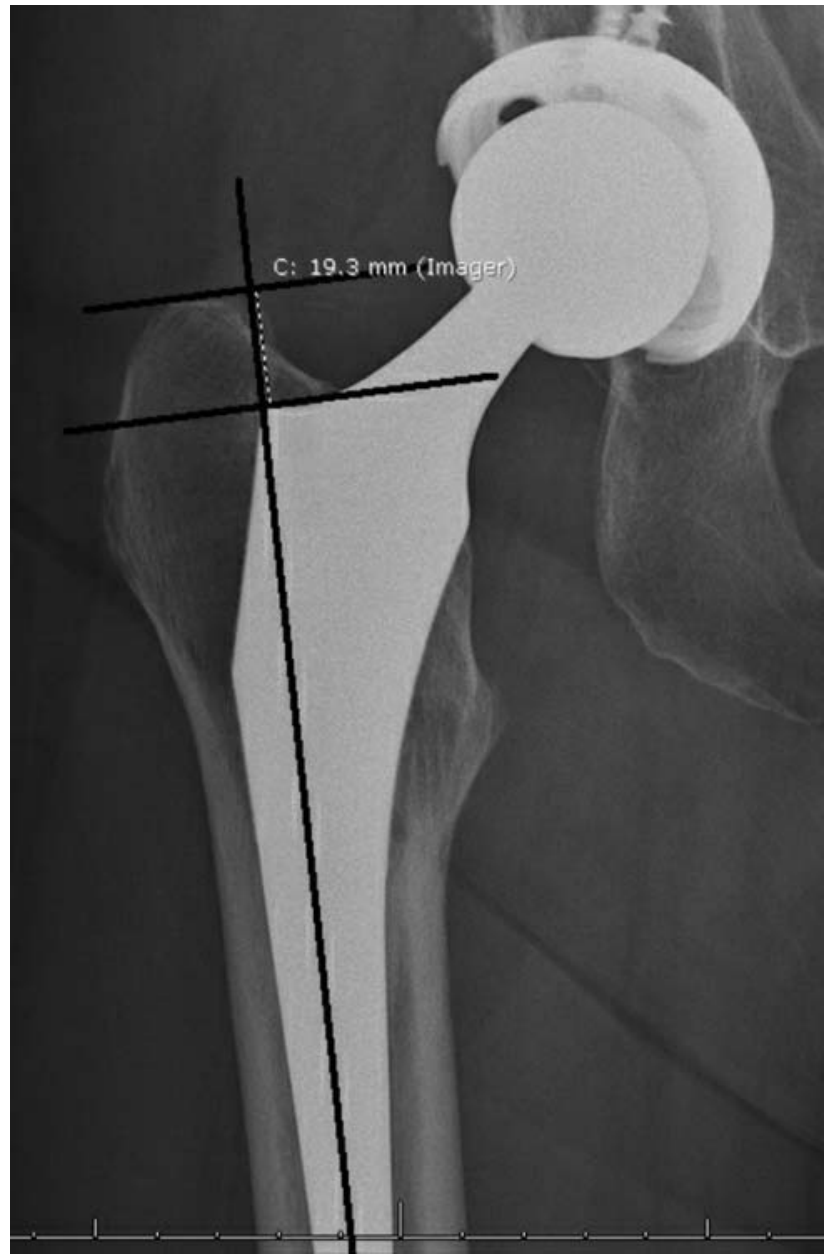

Fig. 1 Example of how subsidence measurements were made on radiographic images.

$40 \%$ but less than $60 \%$ impaired). ${ }^{23}$ We had no cases of CL, CM, or CN (60-100\% impairment).

\section{Statistical Analysis}

Descriptive data are represented as means \pm standard deviation. Independent sample, two-sided $t$-tests were used to test for significant differences between continuous variables and chi-square tests for categorical variables. Multivariable linear regression models were utilized to study the association between independent predictors including age, gender, BMI, stem type, stem alignment, surgical time, and the dependent variable, subsidence. Binary regression models were used to examine the relation of the covariates of age, gender, BMI, stem type, stem alignment, surgical time on the dependent variable, and LOS. Regression coefficients were calculated with $95 \%$ confidence intervals (CIs), which we used to describe significance of association. A $p$-value of less than 0.05 was considered to be significant. All statistical analyses were performed using SPSS v. 25 (IBM Corporation).

\section{Results}

The primary objective of this study was to determine if activity and patient age impacted femoral stem subsidence. In a 22- month period, we identified 821 patients who underwent a primary DAA THA by a single surgeon with 255 qualifying for the SDD cohort and 566 for the MDS cohort ( - Table 1). Statistically significant demographic differences were observed between the two groups with a significantly larger percentage of females and older patients in the MDS cohort $(p<0.001, p<0.001 ;-$ Table 1). Patients with higher BMIs and those who were more at risk according to the ASA physical status were also found more often in the MDS group $(p<0.001$, $p<0.001 ;$ - Table 1 ). While there was a statistical difference in surgical time between the two groups $(69.46 \pm 10.67$ vs. $70.99 \pm 14.32$ minutes, $p<0.001$; - Table 2 ) when controlling for differences in demographic data, there was no clinical

Table 1 Patient demographic data for the two cohorts: sameday discharge (SDD) and the greater than 24-hour discharge groups (MDS)

\begin{tabular}{|c|c|c|c|}
\hline \multicolumn{4}{|c|}{ Patient demographics } \\
\hline & $\begin{array}{l}\text { Same-day } \\
\text { discharge } \\
(n=255)\end{array}$ & $\begin{array}{l}\text { Greater } \\
\text { than } 24 \text { h } \\
(n=566)\end{array}$ & $p$-Value ${ }^{a}$ \\
\hline Age $(y)$ & $\begin{array}{l}58.98 \\
\pm 8.47\end{array}$ & $\begin{array}{l}67.17 \\
\pm 10.27\end{array}$ & $<0.001$ \\
\hline Gender & & & $<0.001$ \\
\hline Female & 127 & 362 & \\
\hline Male & 128 & 204 & \\
\hline BMI $\left(\mathrm{kg} / \mathrm{m}^{2}\right)$ & $\begin{array}{l}26.61 \\
\pm 4.01\end{array}$ & $\begin{array}{l}27.65 \\
\pm 5.07\end{array}$ & $<0.001$ \\
\hline ASA & & & $<0.001$ \\
\hline 1 & 30 & 15 & \\
\hline 2 & 216 & 345 & \\
\hline 3 & 9 & 197 & \\
\hline 4 & 0 & 9 & \\
\hline Median & 1.95 & 2.35 & \\
\hline Race & & & 0.670 \\
\hline White & 232 & 520 & \\
\hline Other race & 23 & 46 & \\
\hline Smoking status & & & 0.022 \\
\hline Current & 19 & 34 & \\
\hline Former & 78 & 230 & \\
\hline Never & 158 & 302 & \\
\hline AM-PAC score & & & 0.006 \\
\hline $\mathrm{CL}$ & 0 & 3 & \\
\hline CK & 12 & 63 & \\
\hline C] & 11 & 15 & \\
\hline $\mathrm{Cl}$ & 12 & 15 & \\
\hline $\mathrm{CH}$ & 89 & 164 & \\
\hline
\end{tabular}

Abbreviations: AM-PAC, Activity Measure for Post-Acute Care; ASA, American Society of Anesthesiologists; BMI, body mass index. ${ }^{a} p$-Values are derived from two-tailed $t$-test or chi-square tests for categorical values. 
significance. Stem type and stem alignment did not significantly differ between cohorts ( $p=0.260, p=0.566$; - Table 2 ).

To account for the statistically significant differences in demographic and surgical data, linear regressions were utilized to compare stem subsidence with a variety of factors. The model showed that of all the variables examined, only increases in LOS and age were found to be associated with higher stem subsidence ( $p<0.001, p<0.001$; - Table 3 ). AMPAC scores were not found to correlate with stem subsidence in our model ( $p=0.634$; - Table 3 ).

Several binary regressions were run to determine if there was a difference in complication rates between the two cohorts when controlling for differences in the demographic data. While one fracture was recorded for the SDD cohort and six for the MDS group, which ranged from 5 days to 1 year postoperatively, models showed that there were no statistical differences in periprosthetic fracture rates $(0.40 \%$ vs. $1.09 \%$, $p=0.995$; - Table 4). There were no dislocations in either cohort. The 90-day readmission rates were also found to be insignificantly different between the groups with only one readmission for the SDD cohort and 24 for the MDS cohort ( 0.39 vs. $2.47 \%, p=0.533$; - Table 4 ). Patients who were readmitted within 90 days had a $53.1 \%$ decreased odds of being in the SDD cohort (odds ratio [OR], 0.469; 95\% CI; $p=0.533$; - Table 4). Readmission results were fully powered to show a significant difference (power of $86.27 \%[\alpha=0.10]$ ).

An additional binary regression was run to determine which variables contributed to a MDS. Models showed that increased age led to a 9.6\% higher OR of being in the MDS cohort ( $p<0.001$; - Table 5). Additionally, higher BMI led to $6 \%$ increase in OR for being in the MDS cohort while being male is associated with a $267 \%$ increased OR ( $p=0.009$; $p<0.001$; - Table 2). Initial high-impairment AM-PAC scores were not associated with longer $\operatorname{LOS}(p=0.630$; - Table 5).

Table 2 Surgical characteristics between the same-day discharge (SDD) and the greater than 24-hour discharge groups (MDS)

\begin{tabular}{|c|c|c|c|}
\hline \multicolumn{4}{|c|}{ Surgical characteristics } \\
\hline & $\begin{array}{l}\text { Same-day } \\
\text { discharge } \\
(n=255)\end{array}$ & $\begin{array}{l}\text { Greater } \\
\text { than } 24 \mathrm{~h} \\
(n=566)\end{array}$ & $p$-Value ${ }^{a}$ \\
\hline $\begin{array}{l}\text { Surgical } \\
\text { time (min) }\end{array}$ & $\begin{array}{l}69.46 \\
\pm 10.67\end{array}$ & $70.99 \pm 14.32$ & $<0.001$ \\
\hline Subsidence (mm) & $\begin{array}{l}0.916 \\
\pm 0.86\end{array}$ & $1.80 \pm 1.91$ & $<0.001$ \\
\hline Stem & & & 0.260 \\
\hline Anthology & 127 & 362 & \\
\hline Accolade & 128 & 204 & \\
\hline Stem alignment & & & 0.566 \\
\hline Neutral & 235 & 531 & \\
\hline Varus & 19 & 29 & \\
\hline Valgus & 1 & 6 & \\
\hline
\end{tabular}

Note: Analysis accounts for differences in demographic data. ${ }^{a} p$-Values are derived from a binary logistic and linear regressions.
Table 3 Multivariate linear regression analysis of stem subsidence

\begin{tabular}{|l|l|l|}
\hline \multicolumn{3}{|l|}{ Linear regression for stem subsidence } \\
\hline & Unstandardized $\beta$ & $p$-Value \\
\hline LOS & 0.823 & 0.002 \\
\hline Age & 0.023 & 0.042 \\
\hline BMI & 0.005 & 0.837 \\
\hline ASA & 0.115 & 0.621 \\
\hline Gender & 0.134 & 0.574 \\
\hline Race & -0.010 & 0.981 \\
\hline Smoking & 0.099 & 0.481 \\
\hline Surgical length & $-3.341 \times 10^{-5}$ & 0.997 \\
\hline Stem & 0.000 & 0.999 \\
\hline AM-PAC & 0.041 & 0.634 \\
\hline
\end{tabular}

Abbreviations: AM-PAC, Activity Measure for Post-Acute Care; ASA, American Society of Anesthesiologists; BMI, body mass index; LOS, length of stay.

${ }^{a} p$-Values are derived from a multivariate linear regression.

\section{Discussion}

With population growth and increased life expectancy, the demand for THA is expected to continue to increase. ${ }^{19}$ At the same time, there are institutional and patient-driven pressures for shorter hospital stays and faster rehabilitation. It has previously been thought that early mobilization places patients at an increased risk of early femoral stem subsidence. This can lead to hip instability, periprosthetic fracture, limb length discrepancy, and other complications, possibly requiring revision surgery. While stem subsidence is a major concern, much of the published literature on early mobilization following THA focuses on patient-centered outcomes and do not examine clinical outcomes. ${ }^{7,24}$ The goal of this study is therefore to report how activity affects stem subsidence among all patients who undergo a cementless primary THA.

Femoral stem subsidence has been found to usually occur within the first few weeks following surgery and remains relatively unchanged between the 3-month and 2-year follow-up. ${ }^{6-8}$ As a result, we were able to collect data on a large patient population who had follow-up radiographs between 3 months and 2 years post-THA. Upon splitting our sample population into SDD and MDS groups and controlling for differences in demographic data, we found that LOS was affected by age, with older patients staying in the hospital for multiple days (OR, 1.092; 95\% CI: 1.07-1.12; $p<0.001$; - Table 5). This confirms previous findings which show that older patients either opt for or are assigned an inpatient admission and are kept longer due to preexisting conditions. $^{4,25}$ Results also showed that higher BMI and being male is associated with a MDS (OR, 1.070, 95\% CI: 1.04-1.11, $p=0.46$; OR, 3.668, 95\% CI: 2.03-4.55, $p<0.001$; - Table 5). Otero et al showed that obesity and the male gender are significant risk factors that affects complication rates in total 
Table 4 Logistic regression analysis of complication data post-THA

\begin{tabular}{|c|c|c|c|c|}
\hline \multicolumn{5}{|c|}{ Logistic regression for complication data } \\
\hline & \multicolumn{2}{|c|}{ Periprosthetic fractures } & \multicolumn{2}{|c|}{ 90-day readmission } \\
\hline & Odds ratio & $p$-Value ${ }^{a}$ & Odds ratio & $p$-Value ${ }^{\mathrm{a}}$ \\
\hline LOS & 0.996 & 0.997 & 0.469 & 0.533 \\
\hline Age & 1.078 & 0.115 & 1.011 & 0.772 \\
\hline BMI & 1.053 & 0.548 & 1.101 & 0.138 \\
\hline Gender $^{\mathrm{b}}$ & 1.972 & 0.447 & 0.709 & 0.709 \\
\hline Race $^{c}$ & 0 & 0.997 & 0 & 0.997 \\
\hline Smoking $^{\mathrm{d}}$ & & 0.739 & & 0.92 \\
\hline Former smoker & $6.7 \times 10^{6}$ & 0.996 & 1.954 & 0.519 \\
\hline Current smoker & $3.4 \times 10^{6}$ & 0.997 & 1.516 & 0.702 \\
\hline ASA & 0.812 & 0.801 & 1.048 & 0.909 \\
\hline Stem & 1.869 & 0.436 & 1.014 & 0.225 \\
\hline Surgical length & 1.05 & 0.005 & 0.999 & 0.972 \\
\hline
\end{tabular}

Abbreviations: ASA, American Society of Anesthesiologists; BMI, body mass index; LOS, length of stay; THA, total hip arthroplasty. ${ }^{a} p$-Values are derived from binary logistic regressions.

${ }^{\mathrm{b}}$ Female gender was used as the reference.

${ }^{c}$ White race was used as the reference.

${ }^{\mathrm{d}}$ Nonsmoker was used as the reference.

joint arthroplasty (TJA) which could explain why these patients were more often kept in the hospital for longer period. ${ }^{26}$ Other studies corroborate these finding and have shown that obesity and being male leads to longer LOS and longer inpatient rehabilitation stays following TJA. ${ }^{27,28}$ Higher ASA scores, which are associated with greater comorbidities, were also shown to lead to longer LOS (-Table 5). These findings coincide with other studies which have shown similar results and correlate this increase in LOS to the fact that these patients are more at risk for complications. ${ }^{27,28}$

When examining the factors which effect subsidence in elective primary DAA THA, we found that increasing age is related to increased stem subsidence. Published results on stem subsidence following cementless THA vary greatly with an average range of subsidence between 0.45 and $2.23 \mathrm{~mm} .{ }^{8,29-34}$ Each cohort consisted of only patients that underwent THA with the DAA and the mean subsidence in our study was within the accepted range noted in the literature which suggests that approach does not affect subsidence outcomes. While excessive stem subsidence was not observed, there was a significant difference between cohorts with the less active MDS group experiencing greater subsidence than the SDD group ( 1.80 vs. $0.92 \mathrm{~mm}, p<0.001)$. Following THA, it has been shown that younger patients may have comparable activity levels to older patients. ${ }^{24}$ If mechanical causes were responsible for subsidence, the expectation would be similar subsidence levels. However, our results showed that aging was associated with a slight increase in subsidence, which implies that another mechanism is affecting the subsidence in these older patients ( $\beta=0.023, p<0.001)$. Additionally, our findings that increased load due to BMI or activity does not affect subsidence
Table 5 Logistic regression analysis of whether a patient remained in the hospital for greater than or less than 24 hours

\begin{tabular}{|c|c|c|}
\hline \multicolumn{3}{|c|}{ Logistic regression for LOS } \\
\hline & Odds ratio & $p$-Value ${ }^{\mathrm{a}}$ \\
\hline Age & 1.092 & $<0.001$ \\
\hline BMI & 1.070 & 0.046 \\
\hline ASA & 9.298 & $<0.001$ \\
\hline Gender $^{\mathrm{b}}$ & 3.668 & $<0.001$ \\
\hline Race $^{c}$ & 0.921 & 0.866 \\
\hline Smoking $^{\mathrm{d}}$ & & 0.698 \\
\hline Former smoker & 1.541 & 0.505 \\
\hline Current smoker & 1.736 & 0.408 \\
\hline Surgical length & 1.025 & 0.082 \\
\hline Stem & 0.606 & 0.078 \\
\hline AM-PAC & & 0.630 \\
\hline $\mathrm{CL}$ & 0.340 & 0.560 \\
\hline CK & 0.106 & 0.745 \\
\hline C] & 1.059 & 0.303 \\
\hline $\mathrm{Cl}$ & 2.516 & 0.113 \\
\hline
\end{tabular}

Abbreviations: AM-PAC, Activity Measure for Post-Acute Care; ASA, American Society of Anesthesiologists; BMI, body mass index; LOS, length of stay.

${ }^{a} p$-Values are derived from a binary logistic regression.

${ }^{b}$ Female gender was used as the reference.

'White race was used as the reference.

${ }^{\mathrm{d} N o n s m o k e r}$ was used as the reference.

"AM-PAC score: " $\mathrm{CH}$ " was used as the reference. 
would also suggest that there is an additional nonmechanical reason for the increase in subsidence with age $(p=0.837)$. While there is some evidence that poor bone quality has been overemphasized, many studies have shown that low BMD, which is associated with aging, will delay osseointegration of the stem and may result in migration. ${ }^{9,12}$ Additional aging effects such as postmenopausal status and osteoporosis have also been linked with increased risk of stem subsidence. ${ }^{9,10}$ Analysis has shown that decreases in BMD such as those related to aging and osteoporosis have a negative effect on the proximal femur resulting in the reduction of bone density of the trochanteric cancellous bone, increased intracortical porosity, and geometric changes. ${ }^{11,12}$ While the scope of our study did not examine the causes of stem subsidence, our results correlated with increased stem subsidence risk associated with comorbidities that directly relate to an increase in age.

While we found that age has a correlation with stem subsidence in both the SDD and MDS group, we determined that early activity after surgery, using SDD as a proxy, does not negatively impact stem subsidence levels, which supports our hypothesis of a nonmechanical mechanism for subsidence. Patients with a SDD were assumed to be more active as they would have to be more mobile in a nonclinical setting. We found that patients who remained in the hospital for longer had higher rates of subsidence than SDD patients $(\beta=0.823, p=0.002)$. While these findings suggest that increased activity does not lead to increased stem subsidence, our statistical analyses did not include comorbidities, which may have contributed to the increased LOS of the MDS cohort. The patients who are chosen for inpatient admission often have a greater number of coexisting comorbidities and may have decreased preoperative ambulatory function which could skew our results. ${ }^{4}$ Since LOS and activity level are not directly comparable, additional research is required to confirm the effect of early activity level on stem subsidence as well as other comorbidities that influence LOS. However, these results suggest that increased postoperative mobilization following direct anterior THA does not negatively impact stem subsidence.

In addition to having no negative effect on subsidence, our data showed that postoperative activity level had little effect on complication data. Results showed no difference in fracture rates or number of dislocations within 90 days between the two cohorts. While not fully powered to show a difference in facture rates between cohorts, our rate of incidence for the MDS group, 1.09\%, corresponded with data from the Mayo Clinic Joint registry which finds an incidence of approximately $1.1 \%$ of periprosthetic fractures in patients who underwent press-fit femur implants as part of a THA, while our SDD group was less than this accepted rate of incidence, $0.40 \%{ }^{35}$ It follows that despite a patient's LOS, the DAA does not negatively impact periprosthetic fracture incidence rates. Additionally, these results suggest that postoperative activity levels do not negatively impact fracture rates. We also found that a MDS was not correlated with a higher likelihood of being readmitted 90 days postoperatively when controlling for factors that we found to effect LOS including age, gender, BMI, and ASA class (OR, 0.469 ; $95 \% \mathrm{CI}: 0.39-1.30, p=0.533$ ). Several variables that we were unable to take into account, which other studies find could be affecting readmission rates, include additional comorbidities and socioeconomic issues. ${ }^{36}$ However, our results suggest that activity level does not affect readmission rates.

While we found that increased age is associated with stem subsidence, our research shows that there are other comorbidities that may contribute to stem subsidence after THA. Comorbidities that may contribute to poor bony integration of the stem, as often seen in older patients and patients with longer LOS, may influence these differences. With further research to identify risk factors for stem subsidence, we can better select the proper technique for stem fixation for each patient and decrease the risk of complications after THA. Such improvements have the potential to increase patient satisfaction and decrease complications and the cost associated with THA.

There are several limitations to this study that should be noted, including its retrospective design. Additionally, all THA cases were performed by a single surgeon at one institution, which may limit the generalizability of the study. Only two THA implant types were utilized, also potentially limiting extrapolation of the results to other stem types. Additionally, our study is limited by the fact that we do not know exactly how much activity or mobility the patients in either cohort had following their procedure. However, our study design attempted to mitigate this limitation as the SDD patients were not told to limit their activity and mobilization at home while the MDS cohort had their activity restricted during their hospital stay due to the environment and staff.

\section{Conclusion}

The results of this study demonstrated that when SDD is taken as a proxy for postoperative activity level, press-fit stems in SDD patients do not subside more than press fit stems in patients who were in the hospital for multiple days (i.e., less active patient cohort). Furthermore, we found that the rates of subsidence and periprosthetic fractures following DAA THA were not higher than those of historical database reports. These findings suggest that femoral stem subsidence is more dependent on the biologic ability of the bone to osseointegrate with the implant and with osteoporosis than the extent of early mechanical loading. We caution surgeons to carefully consider the use of press-fit implants in the more elderly populations regardless of discharge disposition or activity level.

\section{Conflict of Interest}

Dr. Schwarzkopf reports grants and personal fees from Smith \& Nephew and Intellijoint, personal fees from Gauss Surgical, outside the submitted work. Dr. Davidovitch reports other income from Radlink, Schaerer Medical, Exactech, and Medtronics, outside the submitted work. 


\section{References}

1 Berger RA, Jacobs JJ, Meneghini RM, Della Valle C, Paprosky W, Rosenberg AG. Rapid rehabilitation and recovery with minimally invasive total hip arthroplasty. Clin Orthop Relat Res 2004;(429): 239-247

2 Aynardi M, Post Z, Ong A, Orozco F, Sukin DC. Outpatient surgery as a means of cost reduction in total hip arthroplasty: a casecontrol study. HSS J 2014;10(03):252-255

3 Husted H, Holm G, Jacobsen S. Predictors of length of stay and patient satisfaction after hip and knee replacement surgery: fasttrack experience in 712 patients. Acta Orthop 2008;79(02): 168-173

4 Walker WC, Keyser-Marcus LA, Cifu DX, Chaudhri M. Inpatient interdisciplinary rehabilitation after total hip arthroplasty surgery: a comparison of revision and primary total hip arthroplasty. Arch Phys Med Rehabil 2001;82(01):129-133

5 Selvaratnam V, Shetty V, Sahni V. Subsidence in collarless corail hip replacement. Open Orthop J 2015;9:194-197

6 Ström H, Nilsson O, Milbrink J, Mallmin H, Larsson S. The effect of early weight bearing on migration pattern of the uncemented CLS stem in total hip arthroplasty. J Arthroplasty 2007;22(08): 1122-1129

7 Campbell D, Mercer G, Nilsson KG, Wells V, Field JR, Callary SA. Early migration characteristics of a hydroxyapatite-coated femoral stem: an RSA study. Int Orthop 2011;35(04):483-488

8 Ström H, Nilsson O, Milbrink J, Mallmin H, Larsson S. Early migration pattern of the uncemented CLS stem in total hip arthroplasties. Clin Orthop Relat Res 2007;454:127-132

9 Aro HT, Alm JJ, Moritz N, Mäkinen TJ, Lankinen P. Low BMD affects initial stability and delays stem osseointegration in cementless total hip arthroplasty in women: a 2-year RSA study of 39 patients. Acta Orthop 2012;83(02):107-114

10 Mäkinen TJ, Alm JJ, Laine H, Svedström E, Aro HT. The incidence of osteopenia and osteoporosis in women with hip osteoarthritis scheduled for cementless total joint replacement. Bone 2007;40 (04):1041-1047

11 Zebaze RM, Ghasem-Zadeh A, Bohte A, et al. Intracortical remodelling and porosity in the distal radius and post-mortem femurs of women: a cross-sectional study. Lancet 2010;375(9727):1729-1736

12 Moritz N, Alm JJ, Lankinen P, Mäkinen TJ, Mattila K, Aro HT. Quality of intertrochanteric cancellous bone as predictor of femoral stem RSA migration in cementless total hip arthroplasty. J Biomech 2011;44(02):221-227

13 Tian P, Li Z-J, Xu G-J, Sun X-L, Ma X-L. Partial versus early full weight bearing after uncemented total hip arthroplasty: a metaanalysis. J Orthop Surg Res 2017;12(01):31

14 Shabana M, Hafez MA, Ayad K, Abd Elfatah M, Zaky LA. Immediate unrestricted versus graduated weight bearing following primary cementless total hip arthroplasty: a randomized controlled trial. Ann Joint 2017;2:6

15 Woolson ST, Adler NS. The effect of partial or full weight bearing ambulation after cementless total hip arthroplasty. J Arthroplasty 2002;17(07):820-825

16 Markmiller M, Weiss T, Kreuz P, Rüter A, Konrad G. Partial weightbearing is not necessary after cementless total hip arthroplasty: a two-year prospective randomized study on 100 patients. Int Orthop 2011;35(08):1139-1143

17 Mast NH, Impellizzeri F, Keller S, Leunig M. Reliability and agreement of measures used in radiographic evaluation of the adult hip. Clin Orthop Relat Res 2011;469(01):188-199
18 Landis JR, Koch GG. The measurement of observer agreement for categorical data. Biometrics 1977;33(01):159-174

19 Kremers HM, Larson DR, Crowson CS, et al. Prevalence of total hip and knee replacement in the United States. J Bone Jt Surg, Am Vol (CD-ROM Ed) 2014;97:1386-1397

20 Khalily C, Lester DK. Results of a tapered cementless femoral stem implanted in varus. J Arthroplasty 2002;17(04):463-466

21 Alexandersson M, Wang EY, Eriksson S. A small difference in recovery between total knee arthroplasty with and without tourniquet use the first 3 months after surgery: a randomized controlled study. Knee Surg Sports Traumatol Arthrosc 2019;27 (04):1035-1042

22 Haley SM, Coster WJ, Andres PL, et al. Activity outcome measurement for postacute care. Med Care 2004;42(1, Suppl):I49-I61

23 Slavin M. Presentation: AM-PACTM Short Forms: Measuring Rehabilitation Functional Outcomes Across Settings. 2014. p. 88

24 Shah RP, Scolaro JA, Componovo R, Garino JP, Lee G-C. Ceramic-onceramic total hip arthroplasty in patients younger than 55 years. J Orthop Surg (Hong Kong) 2014;22(03):338-341

25 Forrest G, Fuchs M, Gutierrez A, Girardy J. Factors affecting length of stay and need for rehabilitation after hip and knee arthroplasty. J Arthroplasty 1998;13(02):186-190

26 Otero JE, Gholson JJ, Pugely AJ, Gao Y, Bedard NA, Callaghan JJ. Length of hospitalization after joint arthroplasty: does early discharge affect complications and readmission rates? J Arthroplasty 2016;31(12):2714-2725

27 Byrne PA, Gupta S, Hopper GP, Deakin AH, Roberts JL, Kinninmonth AWG. Patient factors associated with shorter length of stay following total hip arthroplasty-a retrospective cohort study. Surg Technol Int 2017;31:197-200

28 Roger C, Debuyzer E, Dehl M, et al. Factors associated with hospital stay length, discharge destination, and 30-day readmission rate after primary hip or knee arthroplasty: retrospective cohort study. Orthop Traumatol Surg Res 2019;105(05):949-955

29 White CA, Carsen S, Rasuli K, Feibel RJ, Kim PR, Beaulé PE. High incidence of migration with poor initial fixation of the Accolade stem. Clin Orthop Relat Res 2012;470(02):410-417

30 Röhrl SM, Li MG, Pedersen E, Ullmark G, Nivbrant B. Migration pattern of a short femoral neck preserving stem. Clin Orthop Relat Res 2006;448(448):73-78

31 Mazoochian F, Schrimpf FM, Kircher J, et al. Proximal loading of the femur leads to low subsidence rates: first clinical results of the CR-stem. Arch Orthop Trauma Surg 2007;127(06): 397-401

32 Leali A, Fetto J. Promising mid-term results of total hip arthroplasties using an uncemented lateral-flare hip prosthesis: a clinical and radiographic study. Int Orthop 2007;31(06):845-849

33 Ince A, Lermann J, Göbel S, Wollmerstedt N, Hendrich C. No increased stem subsidence after arthroplasty in young patients with femoral head osteonecrosis: 41 patients followed for 1-9 years. Acta Orthop 2006;77(06):866-870

34 Cordero-Ampuero J, Peñalver P, Antón R, Galán M, Cordero E. Radiographic subsidence in asymptomatic patients after THR using the furlong active HAP stem. HSS J 2013;9(02):161-165

35 Holley K, Zelken J, Padgett D, Chimento G, Yun A, Buly R. Periprosthetic fractures of the femur after hip arthroplasty: an analysis of 99 patients. HSS J 2007;3(02):190-197

36 Chopra I, Wilkins TL, Sambamoorthi U. Hospital length of stay and all-cause 30-day readmissions among high-risk Medicaid beneficiaries. J Hosp Med 2016;11(04):283-288 